\title{
A população africana na irmandade de Nossa Senhora do Rosário: a cidade da Paraíba e o Mundo Atlântico
}

The African population in Nossa Senhora do Rosário brotherhood: Paraíba city and the Atlantic World

\section{Matheus Silveira Guimarães*}

\begin{abstract}
Resumo: Os estudos sobre o Mundo Atlântico começaram a ser desenvolvidos no período pós-Segunda Guerra Mundial, mas nos últimos trinta anos conseguiram alcançar grande projeção. Atualmente, não podemos pensar a formação histórica do Brasil desconectada das relações estabelecidas pelo Atlântico com a África e a Europa. Instituições que demonstram muito bem isso são as Irmandades Religiosas. Surgidas na Europa da Idade Média, logo elas se expandiram para África e América, sendo importante não só para os interesses europeus nesses continentes, mas para a formação do Mundo Atlântico. Este artigo tem como objetivo analisar a Irmandade de Nossa Senhora do Rosário na cidade da Paraíba do Norte, identificando os elementos da população africana presentes não só na organização da irmandade como no cotidiano desta.
\end{abstract}

Palavras-chave: Paraíba; Mundo Atlântico; Irmandade de Nossa Senhora do Rosário.

Abstract: The studies about the Atlantic World were first developed after World War II, but only in the last thirty years that they have gained in popularity. Nowadays we cannot think about the historic formation of Brazil without considering the relations established with Africa and Europe through the Atlantic. The religious brotherhoods are a very good example of it. Arising in Medieval Europe, soon they expanded their branches to Africa and America and turned into important assets for European interests in these continents. The main objective of this article is to analyze Nossa Senhora do Rosário brotherhood in Paraíba do Norte city, identifying the African populations elements present in the organization and day-by-day life of the institution.

Keywords: Paraíba; Atlantic World; Nossa Senhora do Rosário Brotherhood.

\footnotetext{
" Mestre em História pela Universidade Federal da Paraíba. Possui graduação em história por esta mesma instituição e em Relações Internacionais pela Universidade Estadual da Paraíba. Atualmente é professor do Ensino Básico da Rede Municipal de João Pessoa. É vinculado ao Grupo de Pesquisa Sociedade e Cultura no Nordeste Oitocentista.
} 


\section{Introdução}

A ideia de pensar o Mundo Atlântico se desenvolveu, sobretudo, a partir da década de I950, sendo aprofundada nas últimas três décadas. O principal objetivo dessa abordagem é identificar a formação econômica, social, demográfica, cultural e política das sociedades que compõem o oceano Atlântico. Não podemos pensar os continentes da América, África e Europa isoladamente. Todos estes foram historicamente construídos interconectados pelo oceano'.

Dentre as várias instituições que foram compartilhadas no Mundo Atlântico, destacam-se as irmandades religiosas. Estas tiveram importância fundamental no processo de expansão da Europa e da cristianização de África e América. Contudo, em cada lugar que se instalavam eram apropriadas pelos moradores locais, que as utilizavam como espaços de sociabilidades, construção de solidariedade e disputas políticas. Ao nos debruçarmos sobre a sociedade escravista brasileira dos séculos XVIII e XIX, fica nítida a importância das irmandades religiosas na vida da população africana escravizada.

O objetivo deste trabalho consiste em apresentar a Irmandade de Nossa Senhora do Rosário da cidade da Paraíba do Norte, capital da província da Paraíba, articulada ao Mundo Atlântico. Fundada no início do século XVIII, esta irmandade foi de extrema importância para a população africana da cidade. Em um primeiro momento, apresentaremos três pessoas vindas da África e escravizadas na Paraíba, e que tiveram na Irmandade um importante espaço de sociabilidade. Em seguida, a partir dos estatutos, apresentaremos as principais características dessa instituição e as transformações por ela vividas em cem anos de existência (1767-1867), destacando as influências da África na construção da Irmandade e as disputas internas entre grupos distintos. Por fim, apresentaremos aspectos culturais das festas de Nossa Senhora do Rosário nas ruas da cidade da Paraíba, e como eram importantes espaços não só de diversão mas de reafirmação da identidade africana.

\section{Três personagens e uma irmandade}

Iniciaremos nossa narrativa sobre as irmandades na província da Paraíba do Norte a partir da experiência de vida de três africanos: Francisco Gangá, Quitéria Pereira e Antônio. Cada um viveu experiências distintas na referida província, das quais pouco se

\footnotetext{
${ }^{\text {I }}$ Para aprofundar o conceito de Mundo Atlântico, conferir Morgan e Greene (2009).
} 
consegue captar. Entretanto, duas experiências foram comuns aos três: a viagem atlântica dentro de um navio negreiro e a associação a uma irmandade religiosa na Paraíba. Estas experiências permitiram a conexão entre dois mundos e a reconstrução de suas vidas.

Francisco Gangá é um personagem interessante da cidade da Paraíba oitocentista². É um dos poucos negros que aparecem em várias fontes pesquisadas, demonstrando que havia certa influência na capital da província. A origem de Francisco não é possível de ser identificada nos registros. A partir de seu nome, porém, podemos chegar a algumas conclusões. O termo n'ganga refere-se a sacerdotes ou feiticeiros. De acordo com Mattos (2009, p. 52), n'ganga é sinônimo de sacerdote nas línguas de origem banto. Em O Trato dos Viventes, Luiz Felipe de Alencastro (2000, p. 279) explica que esta era uma "palavra do idioma quimbundo que servia para qualificar tanto os feiticeiros tradicionais como os padres europeus, perpetuando o caráter mágico da intervenção dos sacerdotes". Frente a essas informações, acreditamos que Francisco veio da região centro-ocidental da África e, ao chegar ao Brasil, decidiu recordar-se do continente africano, trazendo no seu novo nome aspectos religiosos de sua terra natal.

Em I838, Francisco já vivia na cidade da Paraíba do Norte na condição de liberto. Dessa maneira, percebemos que ele havia desembarcado no Brasil há um tempo considerável, tendo em vista que para conquistar a carta de alforria era necessário tempo, paciência e esforço da parte dos/as escravizados/as. Neste ano, Francisco Gangá aparece nos registros de batismo da Freguesia de Nossa Senhora das Neves batizando várias pessoas, sendo a maioria africana.

A sua boa relação com a população negra escravizada não se dava apenas pelo fato de já ter vivido sob a condição de cativo, mas por ser uma pessoa com razoáveis condições materiais. De acordo com seu testamento, ele possuía doze casas na capital da província ou seja, ao conseguir a condição de forro, Gangá construiu bens que lhe garantiram segurança econômica e, com isso, poderia dar apoio a seus companheiros ainda escravizados. Ademais, os seus laços de solidariedade não se construíram apenas com a população negra. Francisco Gangá, em seu testamento, também garante que - ao morrer suas posses deveriam ficar com Carlos Holmes, um influente e rico comerciante inglês que se estabeleceu na cidade da Paraíba após a independência. Provavelmente este seria seu exproprietário, com quem construiu uma relação de confiança.

\footnotetext{
${ }^{2}$ A presença de Francisco Gangá na cidade da Paraíba foi identificada nas seguintes fontes: Livros de batismos da Freguesia Nossa Senhora das Neves, I833-6o. Arquivo Eclesiástico da Paraíba (AEPB); Livro de Notas da cidade da Parahyba (I84I - I846). Arquivo do Instituto Histórico e Geográfico Paraibano (AIHGP).
} 
Quitéria Pereira de Sousa foi outra africana importante para pensarmos as relações entre Paraíba e África no Mundo Atlântico. Ela havia nascido na Costa da Mina, região Ocidental do continente africano. Aos oito anos de idade foi trazida para o Brasil. A sua memória já não a permitia lembrar sobre seus familiares. Casara-se com José Pereira de Sousa, assumindo seu sobrenome. Ambos nunca tiveram filhos. Devido a isso, Quitéria desejava deixar suas posses com sua afilhada Anna, que era filha de Antônia de Figueiredo e do Capitão Luiz José Figueiredo, já falecido. Ser comadre e compadre de um “Capitão" demonstra que Quitéria e seu marido possuíam boas relações com pessoas de status social elevado na cidade ${ }^{3}$.

Ao final da década de I850, o africano Antônio foi batizado na Freguesia de Nossa Senhora das Neves. Devido ao ano, conclui-se que ou Antônio estava vindo de outra província e ainda não tinha sido batizado ou vivia na Paraíba há algum tempo sem ter passado por esta cerimônia. $\mathrm{Na}$ ata batismal foi registrada a mudança de proprietário, sendo vendido por José Lucas de Sousa Rangel a Diogo de Albuquerque. Antônio veio de Moçambique (África Oriental) ao Brasil e aqui teve como padrinho Doutor Olimpo Antonio de Miranda ${ }^{4}$.

Francisco, Quitéria e Antônio vieram de regiões distintas da África e chegaram também em momentos distintos. Pelos registros das fontes, provavelmente tenham se conhecido. Ao menos, andaram pelas ruas da cidade da Paraíba em períodos muito próximos. Uma instituição os uniu: a irmandade de Nossa Senhora do Rosário. Antônio havia sido batizado na igreja da Irmandade. O fato de um africano adulto ser batizado nessa igreja nos aponta a possibilidade de ele fazer parte ou ser próximo da Irmandade. Francisco e Quitéria, por sua vez, deixaram em seu testamento a ordem de doação de esmolas para a irmandade. A história desses três africanos demonstra a importância da Irmandade de Nossa Senhora do Rosário para essas pessoas.

\section{A Irmandade de Nossa Senhora do Rosário e o Mundo Atlântico}

O contexto da Idade Média foi marcado pela forte religiosidade e, em alguns momentos, por intensa pobreza. Como alternativa para construir uma relação de ajuda mútua e devoção, surgiram as Irmandades religiosas. Estas, apesar de seu caráter religioso,

\footnotetext{
${ }^{3}$ Livro de Notas da cidade da Parahyba (I84I - I846), fl. I8v. Arquivo do Instituto Histórico e Geográfico Paraibano (AIHGP)

${ }^{4}$ Livros de batismos da Freguesia Nossa Senhora das Neves, I833-6o, fl.33. Arquivo Eclesiástico da Paraíba (AEPB).
} 
seriam compostas por pessoas leigas. A história das irmandades relaciona-se diretamente com o processo de expansão vivenciado pela Europa a partir do século XVI e seu estudo contribui para a compreensão das relações estabelecidas na formação do Mundo Atlântico, sendo constituídas não só no continente europeu mas na África e na América como instrumento de cristianização.

Russel-Wood, um dos principais estudiosos do Mundo Atlântico português, identifica nas irmandades religiosas importantes pilares de unificação do Império. Elas tinham três características fundamentais: fortalecer as práticas cristãs, a preocupação coletiva com o bem estar dos irmãos e arrecadação de fundos para a prática da caridade (RUSSEL-WOOD, 2005, p.192).

Se no contexto europeu as irmandades assumiram um papel fundamental na manutenção da ordem, no Brasil não foi diferente. Elas serviram como espaço de sociabilidades das elites, mas também como oportunidade para a população negra escravizada ou livre/liberta estabelecer vínculos de solidariedade, cooperação e proteção.

as irmandades de pessoas de cor do Brasil representaram uma proteção contra uma sociedade competitiva e dominada pelos brancos, não só para o negro trazido da África como escravo como também para os negros e mulatos nascidos no Brasil, fossem escravos ou libertos. As irmandades constituíam uma resposta associativa a uma necessidade coletiva e individual sentida pelos negros e mulatos da colônia. Essa necessidade pode ser discutida em três categorias: educação religiosa ou socorro espiritual, assistência médica e a busca de identidade (RUSSEL-WOOD, 2005, p.193).

Não podemos esquecer, contudo, do caráter religioso das irmandades. Sua preocupação principal era a garantia de uma morte digna aos membros. Dessa maneira, os/as irmãos/ãs assumiam a responsabilidade de assegurá-la não só materialmente, por intermédio de contribuições, mas também presencialmente ao compartilhar o momento da morte, de tamanha importância à época. Tal aspecto facilitou a participação da população africana nessas instituições, pois para alguns povos da África os funerais possuíam um papel social e cultural (THORNTON, 2004, p. 345). Dessa maneira, todos os compromissos (principal documento das irmandades) tinham espaço reservado para estabelecer as regras de arrecadação de fundos para garantir o funeral de seus membros e como os rituais deveriam ser feitos. 
A relação entre as irmandades religiosas e o continente africano foi fundamental. A presença portuguesa na África remonta ao século XV. Desde os primeiros momentos em que chegaram, os lusos estabeleceram instituições como as irmandades com intuito de facilitar a entrada da religião cristã, e alguns elementos das irmandades foram utilizados pelos africanos tomando como referência suas próprias características culturais. Muitos daqueles que foram sequestrados e escravizados na América perceberam nas irmandades um importante espaço para reconstruir suas vidas. Afinal, nas palavras de Kiddy (20I2, p.I70), já havia "familiaridade dos centro-africanos com os símbolos, rituais e organizações católicas, combinada com uma crença na estrutura hierárquica da sociedade e no papel do ritual dos reis". Lucilene Reginaldo (20II), por exemplo, demonstra a importância das irmandades no processo de cristianização da África, estando presentes desde o século XVI.

Este é um fato importante para pensarmos a formação das irmandades religiosas na Paraíba. Nesta província, havia uma maioria considerável de africanos centro-ocidentais, que chegavam a apresentar cerca de $70 \%$ da população africana. Em segundo lugar estariam os "Mina", que eram cerca de 6\% (GUIMARÃES, 20I5). A partir desses números, conseguimos perceber uma intensa presença de africanos vindo da região central da África. Essa característica é importante, pois demonstra proximidade cultural entre a maioria dos africanos da Paraíba e os símbolos e rituais católicos, que já se faziam presentes na África. Ademais, demonstra uma posição difícil para aqueles que vinham de outras regiões e que acabavam sendo, frente a essas condições, pressionados a se relacionar com os povos bantos.

Apesar de se constituírem como espaços para a construção de laços de solidariedade, as irmandades são, antes de tudo, instituições - e estas carregam consigo os conflitos sociais do tempo e do espaço em que se constroem. Assim, como não poderia ser diferente, as irmandades religiosas no Brasil escravista eram marcadas pela segregação e diferenciação racial, havendo irmandades específicas para pretos, pardos e brancos. Além das distinções externas, as irmandades também eram marcadas por conflitos internos entre diversos grupos, como veremos mais adiante. Junto à população negra, as santidades mais homenageadas foram Nossa Senhora da Conceição (sobretudo para a população parda), Nossa Senhora das Mercês, Nossa Senhora do Rosário e São Benedicto, este último foi bastante popularizado devido a sua pele negra (KARASCH, 200o).

Desde o século XV a Europa vivenciou o fenômeno de culto a Nossa Senhora do Rosário, fundado pelos dominicanos. Esta Santa teria surgido na Idade Média a um cônego na França, ensinando-lhe uma sequência de orações que o ajudaria na luta contra os 
hereges. Com a expansão portuguesa para a África, esse culto foi utilizado para iniciar o processo de avanço sobre os africanos. Assim, boa parte dos africanos vindos para o Brasil já tinham algum contato com as irmandades e suas padroeiras. As irmandades do Rosário chegaram ao Brasil ainda no século XVI, mas se expandiram no século XVIII (BORGES, 2005; MEGALE, 200I).

Mas só a presença duradoura dos portugueses na África e a aproximação de alguns rituais com os povos africanos não são suficientes para explicar a aceitação e utilização da imagem de Nossa Senhora do Rosário entre os negros. Megale (200I, p.43I) defende a facilidade das orações feitas para o Rosário. Como afirmamos, a referida Santa havia ensinado uma sequência de orações caracterizadas pelo Pai-nosso e Ave Maria, que são de fácil compreensão (MEGALE, 200I). Além do mais, os africanos faziam apropriações dos Rosários utilizando-os como talismãs, pois "usado ao pescoço, o poder mágico das suas contas servia de bálsamo protector contra os poderes malignos, o que sem dúvida chamou atenção dos africanos e seus descendentes" (SWEET, 2007, p.243).

\section{A Irmandade de Nossa Senhora do Rosário na Província da Paraíba}

A criação da Irmandade de Nossa Senhora do Rosário na cidade da Paraíba data do início do século XVIII, mais especificamente em I7II (PINTO, I977, Vol. I, p. I06). Alguns anos depois, a Igreja em homenagem a referida Santa foi erguida na capital, servindo como sede da Irmandade (PINTO, I977, Vol. I, p. I25). A construção permaneceu no centro da cidade até o início do século XX, quando foi demolida por ordem do então Bispo da Paraíba 5 .

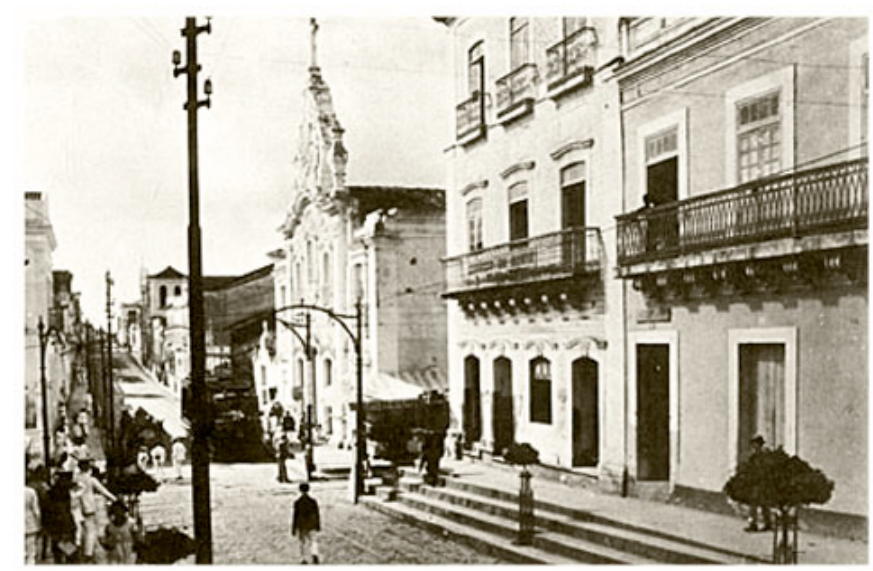

Acervo Walfredo Rodriguez. Disponível em: http://paraibanos.com/joaopessoa/fotos-antigas.htm Acesso em I4 de março de 2016

\footnotetext{
${ }^{5}$ José Flávio Silva (2009, p. 137) traz-nos informações acerca da demolição da referida igreja, ocorrida nos primeiros anos do século XX.
} 
Infelizmente, não possuímos documentação farta sobre as irmandades na Paraíba, e em especial as da população negra. O descaso da administração pública para com os nossos espaços de memória, atrelado a questões metodológicas, teóricas e políticas, fizeram com que várias gerações de historiadores não se interessassem por essa temática, e boa parte dessa documentação se perdeu. Esta deveria ser bastante farta. De acordo com o compromisso da Irmandade de 1867 da referida irmandade

Capitulo $6^{\circ}$.

Das obrigações do Secretario

Art. $17^{\circ}=\mathrm{O}$ Secretario serà sempre pessôa que tenha conhecimento de escripturação, e contabilidade, e que seja de bons costumes, prudente e intelligente; e lhe cumpre:

$\$ I^{\circ} \mathrm{A}$ escripturação de todas as actas, e termos da Mesa.

$\$ 2^{\circ}$ A escripturação do livro da assentamento de irmãos, e irmães, que deve ser feita em dia e com claresa.

$\$ 3^{\circ} \mathrm{A}$ extração das contas dos Irmãos que estiverem atrasados em seos pagamentos, a fim de serem entregues ao Procurador Geral para promover a respectiva cobrança.

$\$ 4^{\circ}$ Fazer toda a mais escripturação de que careça a Irmandade.

$\$ 5^{\circ}$ Assistir a todas as Mesas, e reunisêa, sempre que para ella for avisado (COMPROMISSO da Irmandade de Nossa Senhora do Rosário da Capital, AHWBD, Cx. 049, fl. 4, I867).

Ou seja, quase todas as movimentações da instituição deveriam ser registradas, desde atas de reuniões até pagamentos e matrículas. Tais informações nos permitiriam fazer uma análise mais aprofundada do cotidiano dentro da irmandade do Rosário. Ainda assim, conseguimos ter acesso a importantes documentos organizativos da entidade que nos permitem lançar luz sobre várias questões.

Não encontramos a primeira versão do estatuto de I7II. Porém, ainda no século XVIII (mais precisamente em I767), foi enviada ao Rei de Portugal correspondência solicitando a renovação do compromisso. Desde a Idade Média, a Coroa possuía a autoridade de aprovar e de renovar ou não os regulamentos religiosos. Apenas no século XIX que essa responsabilidade foi passada para as Assembleias Provinciais. Na segunda metade do Oitocentos, no ano de I867, a irmandade do Rosário passou pelo mesmo procedimento de renovação do compromisso e teve o estatuto aprovado em lei pela Assembleia Legislativa. A partir desses dois documentos, analisaremos as mudanças e 
permanências e as formas de organização da irmandade de nossa Senhora do Rosário para podermos identificar importantes elementos da vida da população africana na província da Paraíba.

No Brasil, as irmandades serviram como um importante espaço para reorganização das etnias africanas. Isso se torna mais evidente em algumas regiões com alta densidade de população africana, como é o caso da Bahia. João José Reis (1996) mostra-nos, por exemplo, os conflitos na Bahia entre africanos Minas e Angolas expressos por suas irmandades. O autor defende a ideia de que as irmandades religiosas, mais especificamente entre a população negra, tinham a função de fortalecer os laços de identidade, facilitando a resistência, bem como de ressaltar a diferença entre os grupos étnicos distintos. No caso da Bahia, essas associações estavam separadas não só pela cor (pretos, pardos e brancos) e condição jurídica (escravos, libertos e livres), mas também de acordo com as "nações". Jejes, Angolas, Minas, entre outros, tinham irmandades específicas. Essas distinções foram se tornando mais flexíveis no decorrer do tempo, embora internamente os conflitos continuassem em disputas pela mesa regedora.

Se na Bahia estudos demonstram a formação de grupos étnicos específicos em cada irmandade, não constatamos o mesmo na Paraíba. Esta província possuía uma maioria esmagadora de centro-africanos. Poucos eram os números referentes a outras regiões da África. Dessa maneira, acreditamos ter sido possível uma reorganização que levava em consideração aspectos étnicos, mas não só isso. Em outras regiões isso também ocorreu. Elizabeth Kiddy cita casos do Rio de Janeiro e Minas Gerais, que possuíam grande quantidade de africanos. Segundo ela, mesmo havendo a presença de várias nações, nas irmandades do Rosário o comando de Angolas e crioulos era garantido, o que foi comum em outras regiões. Ao final do Setecentos, tais irmandades começaram a se abrir para outros grupos (KIDDY, 20I2, p. I72) ${ }^{6}$. Foi exatamente esse movimento que identificamos na Paraíba: o controle de Angolas e crioulos das mesas diretoras no Setencentos e a posterior abertura no século XIX.

No estatuto da irmandade de Nossa Senhora do Rosário dos Pretos da capital, identificamos a seguinte regra para participar: "de toda a gente preta, de qual quer nação, que seja, assim livres, como sujeitos, homens e molheres" (AHU_CU_oI4, Cx. 24, D. I83I, 1767). Ao compararmos essa regra com o estatuto da mesma irmandade cem anos depois, percebemos que o requisito para entrada na irmandade continua o mesmo: pretos de qualquer nação. Pardos (libertos, livres ou escravos) e brancos também eram aceitos,

\footnotetext{
${ }^{6}$ Isso também é destacado por Reis (I996).
} 
porém com restrições (COMPROMISSO da Irmandade de Nossa Senhora do Rosário da Capital, AHWBD, Cx. 049, I867, fl.I).

A partir da leitura do primeiro artigo do estatuto da irmandade, é possível identificar referência às origens africanas desta. Os termos "preto" e "nação" eram sinônimos de africanos no século XIX. Isso não significava dizer que outros grupos como brancos e pardos fossem excluídos da irmandade, mas demonstra o protagonismo na organização exercido pelos africanos.

Mesmo não proibindo brancos e pardos, houve a preocupação em restringir a participação desses grupos. Eles poderiam ser irmãos, mas sem direito a voto e nem a ocupar cargo na mesa diretora. Isso demonstra uma preocupação em não ceder espaço político dentro da irmandade para grupos que não fossem de pretos. Havia na irmandade durante o século XVIII uma exceção ao cargo de Escrivão. Este seria ocupado por pessoa branca. Vale ressaltar aqui que essa era uma exceção autointeressada. A sociedade escravista do Brasil era marcada pelo analfabetismo, sobretudo entre os escravizados. Não havia como ocuparem cargos que exigissem a prática da escrita e da leitura - estes, dessa maneira, os brancos poderiam ocupar. Além do mais, havia dois cargos de escrivães, sendo o outro ocupado por pessoa negra. No compromisso confirmado no século XIX, porém, o cargo de escrivão para brancos foi excluído?

Aos brancos e pardos não só era proibido o voto e a participação na mesa. Os irmãos de Nossa Senhora do Rosário permitiam, mas com restrições, a entrada dessas pessoas. O método utilizado foi aumentar a contribuição paga. No compromisso aprovado em I767, os pretos deveriam pagar a quantia de 320 réis $(\$ 320)$ para entrar na confraria. O valor para brancos e pardos seria de 640 réis $(\$ 640)$, o dobro do que era pago pelos pretos (AHU_CU_oI4, Cx. 24, D. I83I, I767). No compromisso de I867 há uma maior flexibilização; os pardos e brancos pagariam o mesmo valor de entrada que os pretos. Além disso, escravos deveriam pagar menos de entrada em relação aos livres, sendo 500 réis e 1000 réis respectivamente (COMPROMISSO da Irmandade de Nossa Senhora do Rosário da Capital, AHWBD, Cx. 049, fl. 2, I867).

As disputas pela mesa diretora não se davam apenas entre pretos, brancos e pardos. Havia conflitos entre os próprios africanos e crioulos. Para compreender esses embates,

\footnotetext{
${ }^{7}$ Em I867, também temos a aprovação do Compromisso da Irmandade de São Benedicto, dos escravos do convento de Santo Antônio, na capital. Neste compromisso, há cargos para exercer, basicamente, a mesma função, mas que são destinados para pessoas brancas, por serem cargos relacionados à habilidade da escrita. São eles: o tesoureiro e tesoureiro externo; o escrivão, e o escrivão externo. Os "externos", que são ocupados por brancos, não podem ter nenhum poder de decisão, restando-lhes apenas a função burocrática da escrita. Cf. COMPROMISSO da Irmandade do Glorioso São Benedicto, AEPB, I867. Naiara Alves (2006) também faz uma discussão sobre esse caso.
} 
vamos apresentar como esta se organizava. A organização da mesa da Irmandade de Nossa Senhora do Rosário dos Pretos da cidade de Paraíba do Norte contava com seis crioulos e seis africanos de Angola. Se a irmandade previa pretos e pretas de várias nações e sua mesa era composta apenas por crioulos e Angolas, isso demonstra uma preocupação no controle da irmandade por estes dois grupos.

A hierarquia era mantida a partir da condição de se pagar pelos cargos. Em I767, o Juiz, maior cargo da Irmandade, deveria ser forro e pagar anualmente a quantia de dois mil réis (2\$0oo). Os Reis e Rainhas pagariam I\$600 e os demais irmãos da mesa pagavam 640 réis (\$640), valor bem abaixo do Juiz e dos Reis. Aqueles que ainda não compunham a mesa ficariam responsáveis pelo valor de 320 réis (\$320) (AHU_CU_OI4, Cx. 24, D. I83I, 1767). Quanto mais importante o cargo, mais caro deveria se pagar. Como essas pessoas conseguiam dinheiro?

Só poderia ser juiz quem estivesse em liberdade. Esse aspecto demonstra, em primeiro lugar, que a hierarquia social de líberos/livres sobre escravizados se mantinha. Em segundo, a essas pessoas haveria maiores condições de circulação e possibilidade de conseguir o dinheiro necessário para o cargo. Reis e Rainhas poderiam ser escravizados/as. Entretanto, para assumir essa posição havia a necessidade de autorização do senhor ${ }^{8}$. Frente a essa situação, a hipótese de Naiara Alves vem à tona:

Reis poderiam, portanto, serem financiados por homens influentes da sociedade e a medida que se deixavam cooptar, passavam a dever favores e a conduzir as irmandades da forma que melhor agradasse aos seus "patrocinadores". Dentro da própria instituição poderiam existir lideranças diversas que disputariam a direção da instituição, o que geraria, formas diferenciadas de conseguir promoções e eventualmente a eleição para Rei ou Juiz, dependendo da confraria. Irmandades antigas e detentora de muitos bens ficavam visadas e eram desejadas por grande parte da comunidade, no caso da Província da Parahyba era o que ocorria com a Irmandade de Nossa Senhora do Rosário da Capital, por ser uma das mais antigas e ricas sofria pressões, inclusive de outras irmandades que questionavam financiamentos e empréstimos do governo destinados para esta instituição, considerada já suficientemente rica, e com plenas condições de se alto sustentar (ALVES, 2006, p. 89).

\footnotetext{
${ }^{8} \mathrm{O}$ artigo $8^{\circ}$ do Compromisso refere-se aos Reis, Rainhas, Juízes e Juízas. A redação do referido artigo dá a entender a possibilidade de que os juízes/as possam também ser escravos. Como o artigo anterior determina que esse cargo só pode ser exercido por forros, acreditamos que este tenha sido uma imprecisão da escrita do compromisso.
} 
Não há dúvidas de que o interesse em controlar os espaços políticos das irmandades era grande. Para os senhores, era importante ter alguém de confiança assumindo o cargo de juiz. Mas os interesses não eram apenas dos proprietários. A população negra, independente de sua condição social, também desejava interferir nesse processo sem ter que ceder aos senhores. Assim, mesmo levando em consideração a possibilidade de intervenção externa nas irmandades, também não podemos perder de vista a preocupação em manter a autonomia da instituição, pois era o único lugar onde os africanos e negros em geral poderiam ter acesso a um prestígio na sociedade ${ }^{9}$. Nesse sentido, acrescentamos que haveria outras formas de conseguir dinheiro sem que necessariamente pelos senhores.

Comparando os estatutos de 1767 e I867, percebemos que o requisito da presença de Angolas e crioulos na formação das mesas diretoras foi retirado. Os nossos personagens iniciais (Francisco Gangá, Quitéria Pereira de Sousa e Antônio) viveram na cidade da Paraíba do Norte por volta das décadas de I830, I840 e I850. Não sabemos quando houve essa mudança no estatuto da Irmandade. Porém, fica-nos evidente que, por um tempo, dois desses personagens não conseguiriam ter posição de destaque na instituição. Quitéria era da Costa da Mina. Antônio era de Moçambique. Se nesses cem anos, o estatuto transformou-se nesse sentido, não podemos excluir a hipótese de que conflitos internos levantados por pessoas vindas de regiões da África como Quitéria e Antônio possam ter mudado essa situação. Além do mais, após o ano de I850, com o fim do tráfico atlântico de pessoas, a quantidade de africanos na Paraíba reduziu. Assim, espaços como as irmandades podem ter alterado suas disputas internas entre africanos. Os grupos minoritários, como os Minas e Moçambique, podem ter pressionado uma maior participação na Irmandade.

Outro aspecto importante a se destacar sobre a irmandade de Nossa Senhora do Rosário na Capital diz respeito à participação das mulheres. No estatuto de I767, em todos os momentos há o respeito à questão de gênero no documento. No estatuto não há referência apenas aos "irmãos", mas também às "irmãs". A presença das mulheres era importante em muitas dessas irmandades com participação africana, pois

os descendentes africanos seguindo uma lógica pertencente à cultura de seus antepassados, aceitavam e valorizavam o papel da mulher dentro do ambiente religioso. Transportando esta participação para suas irmandades, prestigiando suas rainhas, e registrando em suas ordens de

\footnotetext{
${ }^{9}$ Mariza Soares (2OII) propõe serem as irmandades lugares onde essas pessoas poderiam exercer uma cidadania não possível na sociedade escravista.
} 
compromisso a existência de uma escrivã e de uma juíza (ALVES, 2006, p. $70)$.

Além da participação das mulheres, não podemos esquecer que as irmandades eram compostas por pessoas de várias condições sociais: escravizadas, libertas e livres. Esse aspecto é importante para pensarmos as alianças construídas por esses grupos, pois a irmandade era um espaço interessante para firmar amizades e vínculos espirituais com pessoas de condições sociais melhores, o que não impedia as disputas por espaço político interno a tais instituições (LIMA, 20I3).

Para concluir a discussão sobre as disputa internas na Irmandade de Nossa Senhora do Rosário da Paraíba, não podemos esquecer os já citados cargos de Rei e Rainha. Estes são quase sempre os mais importantes. Isso só pode ser explicado se pensarmos na diáspora, pois

Líderes africanos, fossem eles chefes de pequenas organizações sociais ou reis de grandes Estados, tinham posições rituais importantes que mediavam vários níveis de relações sociais, religiosas e políticas. Essas lideranças centro-africanas estavam no topo da uma bem entendida hierarquia que definia a posição de uma pessoa na sociedade dos vivos e também incluía o mundo invisível que englobava os ancestrais e/ou espíritos, os ainda não nascidos e também os animais, plantas e objetos inanimados. Elas faziam a mediação, por meio de ações rituais, entre a sociedade e o ambiente natural, e entre os vivos e os mortos. Os reis africanos uniam as pessoas umas às outras e as ligavam com tudo o que existia. Conectavam o que os ocidentais definem como o sagrado e o profano, mas que para a cultura africana eram elementos inseparáveis (KIDDY, 20I2, p. I68).

Os povos centro-ocidentais da África possuíam culturalmente forte influência dos Reis e Rainhas. Dessa maneira, ao se utilizarem dos espaços das irmandades religiosas, muitos africanos perceberam a possibilidade de representar essas figuras como uma tentativa de memória do continente africano. Os rituais de coroação de reis foram registrados desde o século XVII, no século seguinte eles se tornam mais comuns. Geralmente, eram denominados Reis e Rainhas do Congo, demonstrando a presença dos povos bantos (centro-ocidentais) nesse processo (KIDDY, 20I2). Era na coroação dos Reis e 
Rainhas que aconteciam as festas e que as expressões culturais africanas eram postas na rua e assistidas pela população branca.

\section{Festas de Nossa Senhora do Rosário e a Coroação de Reis na Paraíba}

Já citamos as experiências de Francisco Gangá e Quitéria Pereira de Sousa. Ambos, ao pedirem para o escrivão Joaquim Segismundo fazer seu testamento, lembraram a necessidade de deixar uma contribuição para a irmandade de Nossa Senhora do Rosário. As chamadas esmolas eram as principais fontes de arrecadação de fundos da instituição, assim como o pagamento feito no ato de entrada na irmandade. De acordo com o levantamento feito por Maria Vitória Lima

\footnotetext{
Existia nas irmandades a figura do esmoler [sic], que percorria as ruas das povoações, das vilas e das cidades para recolher as esmolas, nos sábados ou domingos. Somente quando as esmolas não eram suficientes era que as Irmandades usavam os rendimentos do seu patrimônio para complementar os gastos que seriam realizados com a festa (LIMA, 2013, p. 9I).
}

Essa arrecadação tinha, basicamente, dois objetivos: a festa da padroeira e a organização do funeral de qualquer irmão que falecesse. Este ritual não era, necessariamente, caracterizado pela tristeza. Como nos demonstra João José Reis (I99I), morrer era também uma festa. De acordo com ele

clima de festa, com dança acompanhada por palmas e percussão africanas. A isso somava-se o foguetório, que se tornou mais animado com a saído do cortejo, sendo o morto levado numa rede coberta por um pano mortuário com o desenho de uma grande cruz (REIS, I99I, p.I2I).

Diferente da cultura ocidental cristã, vários povos africanos representavam a morte de outra maneira. Não apenas o choro e a tristeza marcavam o ritual, mas longas procissões com música e dança (KARASCH, 2000, p. 337). Além de um ritual que garantia a entrada do morto no outro mundo, os funerais eram importantes espaços para socialização e diversão. De acordo com o estatuto da irmandade de Nossa Senhora do Rosário da Capital, seguia-se 
do cemitério para a Igreja, onde era feita uma sequência de orações. Provavelmente, com a conclusão dessa cerimônia começava a festa.

Havia também a data mais importante do ano para as irmandades religiosas: o dia da padroeira. Geralmente, a festa ocorria no início de outubro. De acordo com o estatuto de 1767, os irmãos, liderados pelo juiz e os membros da mesa, recolhiam as esmolas, que eram registradas ao final da festa. No domingo seguinte, ocorria a coroação dos Reis e Rainhas, que recebiam as varas dos juízes e, em seguida, assistiam à missa.

Mesmo com as transformações vividas no tempo, alguns dos elementos culturais presentes na irmandade de Nossa Senhora do Rosário estão presentes no sertão da Paraíba. Identificamos estatutos em três cidades do interior: Sousa, Alagoa Nova e Alagoa Grande. Em todas essas, a figura do Rei e da Rainha são fundamentais. Na década de 1970, Roberto Benjamin (1977) fez um estudo de campo sobre a festa da irmandade. De acordo com o autor, a interiorização ocorrida nos séculos XVII e XVIII com a expansão da pecuária, a irmandade e a festa de Nossa Senhora do Rosário foram levadas pela população negra para o sertão da Paraíba. A festa era marcada pela coroação dos reis e das rainhas do Congo, havendo referências diretas às origens africanas.

No início do século XX, mais especificamente em 1907, o folclorista Ademar Vidal presenciou e descreveu uma dessas festas de coroação do rei do Congo, na cidade da Paraíba. Em sua descrição fica nítida a influência da África na elaboração da cerimônia. Em suas palavras,

Ainda se fala em Angola e Loanda, sendo também muito vivas outras reminiscências africanas, aliás facilmente constatável numa linguagem com interferências incompreensíveis. Mas que não deixa dúvida tratar-se de algum sub-dialeto em que a África é fértil (VIDAL, s/d, p. 79).

As palavras não eram as únicas influências africanas sofridas pelos irmãos e irmãs do Rosário na cidade da Paraíba. As descrições e reminiscências da África ainda eram presentes, mesmo após o fim da escravidão.

$\mathrm{Na}$ voz dos que tomam parte nas execuções de autos é que a gente pode bem medir a tristeza do povo transplantado com violência para outro meio social. Prepondera a nostalgia expressa na recordação mencionada de Loanda e Angola (Congo raramente). Na resistência ao embarque. Nas travessias oceânicas. Nos barcos sujos. No sofrimento da separação pra sempre. Todos esses aspectos se acham fixados na psicologia social dos negros que cantam e dançam Congo (VIDAL, s/d, p. 87). 
Além da flagrante tristeza expressa nas recordações do ritual, havia muita dança e música. No sertão, as lembranças da África também eram presentes em versos como "meu pretinho do Congo / donde vem nessa hora / d'embarc'aruanda e / vamos pr'angola". Mais adiante o canto se expressa com "aquela dança qui dancemo quando / viemo de barca prá caluanda" (BENJAMIN, I977, p. II-I2).

No início do século XX a festa continuava a acontecer na mesma data, primeira semana de outubro. Os detalhes eram organizados no sábado que antecedia a festa, com missa e procissão para a arrecadação das esmolas. No domingo, havia nova missa e o início da festa. Ao final da manhã, duas alas se formavam com o rei e a rainha ao centro e saíam em cortejo pela cidade em silêncio. Paravam nas casas de pessoas das elites, onde começava a dança e música, movida pelo maracá e viola.

Várias das expressões culturais presentes no atual Nordeste surgiram nas festas de Nossa Senhora do Rosário dos Pretos. Uma delas foi o Maracatu, que até o início do século XX era muito forte na cidade da Paraíba do Norte. De acordo com as descrições feitas por Ademar Vidal, as apresentações do Maracatu percorriam o centro da cidade, onde em cada igreja se tocava e dançava. A participação popular era grande, sendo protagonizada por pessoas negras. À população branca cabia o papel de espectadora. As pessoas negras da festa vestiam vermelho, os homens com túnicas e as mulheres com saias e turbantes. O rei e a Rainha lideravam e eram os mais bem vestidos da festa. Em cada igreja paravam. O Rei e Rainha falavam para as pessoas que os seguiam. A festa continuava com muita música, bebida e dança (VIDAL, s/d, p. 68).

Esses elementos da festa demonstram que, mesmo se passando muitos anos após o fim do tráfico de africanos para o Brasil, as experiências vividas e as práticas culturais dos povos vindos de África permaneciam nas lembranças e vida da população negra da Paraíba do Norte, sobretudo, daqueles vindos das regiões centro-ocidentais do continente.

\section{Considerações finais}

Buscamos apontar as várias facetas da irmandade de Nossa Senhora do Rosário da cidade da Paraíba do Norte. Infelizmente, a escassez da documentação não nos permitiu avançar mais nas considerações. Ainda assim, alguns pontos podem ser destacados sobre essa questão. 
A irmandade construiu-se na Paraíba do Norte no início do século XVIII, permanecendo até o século XX. Nesse intervalo, conseguimos identificar algumas transformações na instituição e presença de povos africanos. Estes provavelmente já conheciam Nossa Senhora do Rosário, e ao chegarem ao Brasil, perceberam a necessidade de se construir um espaço de sociabilidade entre eles. No compromisso, garantiram a presença de crioulos e Angolas com o objetivo de influenciar as decisões da mesa entretanto, a irmandade era aberta para outros grupos e "nações". Dessa maneira, os conflitos internos por espaços de poder foram grandes. Não conseguimos identificar nenhuma outra irmandade com presença de africanos na cidade. Em contrapartida, percebemos a presença de pessoas de várias regiões da África, como os Minas e Moçambique. Esses fatores acabaram interferindo também na retirada do requisito que garantia a presença de Angolas e crioulos na direção da instituição, o que, ao menos em tese, tornou a mesa mais flexível.

As hierarquias internas também eram estabelecidas pelos cargos, entre os quais se destacam o de Juiz e os Reis e as Rainhas, e cada um tendo um preço específico para que pudesse ser ocupado. As disputas e presenças de pardos e brancos também foram características apontadas nos estatutos. Permitiam a presença desses grupos, mas dificultavam sua entrada e proibiam sua participação em cargos importantes.

Os rituais funerários eram o principal objetivo da existência dessas instituições, que garantiam um procedimento específico para esses momentos. Além da morte, as festas eram os momentos importantes do ano. Não só devido ao culto a Nossa Senhora do Rosário, mas ao destaque dado às pessoas negras que protagonizavam a cerimônia, cantando, dançando e brincando. Muitas das práticas culturais desenvolvidas nos século XVIII e XIX, mesmo com as transformações, permaneceram no cotidiano da cidade até o século XX. Em cada festa eram retomadas as reminiscências de todas as pessoas sequestradas na África, submetidas à viagem atlântica e escravizadas no Brasil. Dessa maneira, as irmandades de Nossa Senhora do Rosário nos apontam vários elementos do Mundo Atlântico. Estudá-las permite-nos pensar as articulações criadas entre Europa, Brasil e África.

\section{Referências}

\section{Fontes}

\section{- Arquivo Eclesiástico da Paraíba (AEPB)}


Livros de batismos da Freguesia Nossa Senhora das Neves, I833-60.

I - I833-I84I

II - I846-I850

III - I850-I857

IV - I857-I 863

COMPROMISSO da Irmandade do Glorioso São Benedicto, I867.

- Arquivo do Instituto Histórico e Geográfico Paraibano (AIHGP)

Livro de Notas da cidade da Parahyba do Norte (I84I-I846).

- Arquivo Histórico Ultramarino (A.H.U.)

AHU_CU_OI4, Cx. 24, D. I83I 1767.

- Arquivo Histórico Waldemar Bispo Duarte (AHWBD)

Caixa 049, I867.

- COMPROMISSO da Irmandade de Nossa Senhora do Rosário dos Pretos da Capital, I867

Bibliografia

ALENCASTRO, Luís Felipe. O Trato dos Viventes: formação do Brasil no Atlântico Sul (séculos XVI e XVII). São Paulo: Companhia das Letras, 2000.

ALVES, Naiara Ferraz Bandeira. Irmãos de cor e de fé: irmandades negras na Parahyba do Século XIX. Dissertação (Mestrado). Programa de Pós-Graduação em História. Centro de Ciências Humanas Letras e Artes. Universidade Federal da Paraíba. João Pessoa, 2006. BENJAMIN , Roberto. Congos da Paraiba. Rio de Janeiro : Fundação Nacional de ArteFUNART, 1977 .

BORGES, Célia Maia. Escravos e libertos nas Irmandades do Rosário: devoção e solidariedade em Minas Gerais - séculos XVIII e XIX. Juiz de Fora: UFJF, 2005.

GUIMARÃES, Matheus S. Diáspora Africana na Paraíba do Norte: trabalho, tráfico e sociabilidades na primeira metade do século XIX. Dissertação (Mestrado) - UFPB/CCHL. João Pessoa, 20I5.

KIDDY, Elizabeth W. Quem é o rei do Congo? Um novo olhar sobre os reis africanos e afro-brasileiros no Brasil. In.: HEYWOOD, Linda M. (org). Diáspora Negra no Brasil. Tradução Ingrid de Castro Vompean Fregonez, Thaís Cristina Casson e Vera Lúcia Benedito. 2 ed. São Paulo: Contexto, 2012. p. I65-I9I. 
LIMA, Maria Vitória Barbosa de. Liberdade interditada, liberdade reavida: escravos e libertos na Paraíba escravista (Século XIX). Brasília: FCP, 2013.

MATTOS, Regiane Augusto de. As sociedades africanas. In: História e cultura afro-brasileira. 2 ed. São Paulo: Contexto, 2013.

MEGALE, Nilza Botelho. Invocações da Virgem Maria no Brasil: história - iconografia - folclore. 6 ed. Petrópolis: Vozes, 200I.

MORGAN, Philip; GREENE, Jack P. The present state of Atlantic History. Atlantic History: A Critical Appraisal. New York: Oxford University Press, 2009.

PINTO, Irineu. Datas e notas para a história da Paraíba. João Pessoa: Universitária/UFPB, 1977. 2 Vols.

REGINALDO, Lucilene. Os Rosários dos Angolas: Irmandades de africanos e crioulos na Bahia Setencentista. São Paulo: Alameda, 20II.

REIS, João José. Magia jeje na Bahia: a invasão do calundu do Pasto de Cachoeira, I785. Revista Brasileira de História. Vol. 8, n. I6, 1988, p. 57-8I. Identidade e diversidade étnica nas Irmandades Negras no tempo da Escravidão. Tempo. v.2, n.3, 1996. p. 7-33. - A morte é uma festa: ritos fúnebres e revolta popular no Brasil do século XIX. São Paulo: Companhia das Letras, I99I.

RUSSEL-WOOD, A J. R. Escravos e libertos no Brasil colonial. Tradução Maria Beatriz Medina. Rio de Janeiro: Civilização Brasileira, 2005.

SILVA, José Flávio. Progresso e destruição na cidade da Parahyba: cidade dos jardins. João Pessoa: Editora Univesitária/UFPB, 2009.

SOARES, Mariza de Carvalho. Política sem cidadania: eleições nas irmandades de homens pretos, século XVIII. In.: CARVALHO, José Murilo de; CAMPOS, Adriana Pereira (orgs). Perspectivas da cidadania no Brasil Império. Rio de Janeiro: Civilização Brasileira, 20II.

SOUZA, Marina de Melo e. Reis negros no Brasil escravista: história da festa de Coroação de Rei Congo. Belo Horizonte: Editora da UFMG, 2002.

SWEET, James H. Recriar África: Cultura, parentesco e religião no mundo afro-português (I44II770). Tradução João Reis Nunes. Lisboa: Edições 70, 2003.

THORNTON, John Kelly. A África e os africanos na formação do mundo atlântico I4Oo - I8oo. Tradução Marisa Rocha Mota. Rio de Janeiro: Elsevier, 2004.

VIDAL, Ademar. Práticas e costumes afro-brasileiros. Mimeografado, s/d. 